\title{
PENSANDO FRONTEIRAS E TERRITORIALIDADES EM DOIS BAIRROS DE SÃO LUÍS (MA)
}

Maysa Mayara Costa de Oliveira $ه$ 


\section{RESUMO}

Este trabalho busca fazer uma análise dos bairros da Camboa e Liberdade, localizados no centro de São Luís, levando em conta as pluralidades e especificidades que compuseram a produção do espaço urbano da capital maranhense. A formação desses bairros apresenta características muito peculiares: primeiro, geograficamente, os bairros estão situados à margem do rio Anil, o que possibilita a atividade de pesca, a criação de pequenos animais, como também a construção de moradias improvisadas; segundo, os bairros agregam um grande contingente de famílias migrantes dos territórios de Alcântara e litoral ocidental maranhense, dando significado a esses locais como espaços de resistência e reprodução das culturas das comunidades migrantes, tanto que os bairros ganharam a titulação de quilombo urbano. Nesse sentido, busco analisar os bairros como espaços de fronteira pela relação que seus moradores estabelecem com seus locais de origem, assim como espaços, também, de resistência e reprodução de modos de vida.

Palavras-chave: Camboa; bairros; Liberdade; territórios; resistência.

\section{THINKING A BORDERS AND TERRITORIALITIES IN TWO NEIGHBORHOODS FROM SÃO LUIZ (MA)}

This work seeks to analyze neighborhoods of Camboa and Liberdade, located in the center of São Luís, taking into account the pluralities and specificities that the made up the prodution of space in the capital; The formation of these neighborhoods has very peculiar characteristics. First, the neighborhoods are geographically located on the banks of the River Anil, which allows fishing, the creation of small animals, as well as the construction of makeshift houses. Second, the neighborhoods add a large contingent of migrant families from the territories of Alcântara and western coast of Maranhão, giving meaning to these places as spaces of resistance and reproduction of the cultures of the migrant communities, not so much, the neighborhoods gained the title of urban quilombo. In this sense, we seek to analyze the neighborhoods as frontier spaces by the relationship that their residents establish with their places of origin; as well as spaces of resistance and reproduction of ways of life.

Keywords: Camboa; neighborhoods; Liberdade; territories; resistance

\section{PENSANDO EN FRONTERAS $Y$ TERRITORIALIDADES EN DOS BARRIOS DE SÃO LUÍS}

Este trabajo busca analizar los barrios de Camboa y Liberdade, ubicados en el centro de São Luís, teniendo en consideración las pluralidades y especificidades que determinaron la producción del espacio urbano en la capital. La formación de estos barrios tiene características peculiares. En primer lugar, geográficamente, los barrios se ubican a orillas del río Anil, lo que permite realizar actividades de pesca, la crianza de pequeños animales, así como la construcción de casas improvisadas. En segundo lugar, los barrios agregan un gran número de familias migrantes de Alcântara y la costa oeste de Maranhão, dando le a estos lugares el sentido de espacios de resistencia y reproducción de culturas de las comunidades migrantes, no es por acaso que los barrios ganaron el título de quilombo urbano. Por lo tanto, buscamos analizar a los barrios como espacios fronterizos debido a la relación que sus habitantes establecen con sus lugares de origen; así como espacios de resistencia y reproducción de formas de vida.

Palavras -claves: Camboya; barrios; Libertad; territorios; resistencia 


\section{INTRODUÇÃO}

Este artigo constitui-se como parte de uma empreitada de pesquisa que tenho realizado no bairro da Camboa, no centro de São Luís desde 2015, com moradores de um residencial construído no bairro. Tal pesquisa tem se desenhado também em compreender um pouco mais sobre as sociabilidades e territorialidades encontradas no bairro.

O bairro da Camboa está localizado ao lado esquerdo do rio Anil e é circunvizinho de outros bairros, como Liberdade e Fé em Deus. Juntos, eles integram os 11 bairros que constituem o Centro Histórico da capital maranhense. Em seu histórico, o bairro da Camboa se consolidou com a fundação da Fábrica de Fiação e Tecido, no século XIX, que foi sendo ocupado pelo operariado que trabalhava nela. Nas décadas de 1970 e 1980, os intensos fluxos migratórios causados pelos conflitos agrários e grandes empreendimentos no estado, como a implantação da base de Alcântara, contribuíram para maior adensamento populacional nos bairros. Muitas famílias encontraram nas áreas de mangue a possibilidade de acesso a terra e moradia, dando uma característica aos bairros como um "cinturão de pobreza”, por causa das condições de vida às margens do rio Anil.

Em 2008, os bairros passaram por um processo de reurbanização, com os investimentos do Programa de Aceleração do Crescimento (PAC).
Muitas famílias foram retiradas de palafitas para serem realojadas em conjuntos habitacionais construídos pelo programa. Também foram construídas praças, quadras de esportes, quiosques, reforma do cais para os pescadores, além da avenida IV Centenário, construída à margem do rio Anil interligando o bairro da Camboa à Avenida dos Franceses, uma das principais avenidas da capital.

Em novembro de 2019, a área que compõe os bairros da Camboa, Liberdade e Fé em Deus foi reconhecida como quilombo urbano, assim, o Quilombo da Liberdade passa a ser considerado o maior quilombo urbano da América Latina. A área possui uma confluência de elementos da paisagem urbana e natural, já que o rio e o mangue compõem a paisagem natural e adentram o espaço do concreto e do asfalto. Os coloridos dos grafites nos muros, nas casas, nas colunas das pontes contrastam com o movimento de vaivém dos barcos que ancoram ali debaixo. $\mathrm{O}$ cenário mudou, mas as atividades de pesca ainda se perpetuam na Camboa, que antes era apenas uma vila de pescadores.

Esses bairros podem representar muito bem as pluralidades e especificidades da composição do espaço urbano da capital ludovicense, um misto de várias realidades em um espaço que evoca, ao mesmo tempo, os problemas das grandes cidades e a tranquilidade do rio e do mar que se 
encontram em sua paisagem natural. Locais que têm grande expressão para a cultura do estado, com grupos de bumba-meu-boi, blocos tradicionais de forte religiosidade e que respiram os sotaques da cultura da Baixada Maranhense, herança de culturas migrantes.

Nesse aspecto, chamo atenção para pensar a cidade de São Luís dentro de suas especificidades locais. Ao mesmo tempo que essa cidade possui características de grandes centros, como a influência que a capital exerce para outras cidades, regiões ou outros países com serviços, equipamentos ou fluxos econômicos mobilizados por grandes empreendimentos, dentre eles porto, estrada de ferro, aeroporto, base de lançamento de foguetes... Também possui outras singularidades, como alguns de seus bairros representarem a extensão de uma vida camponesa, expressão de territorialidades culturais fortes, sendo lugar de reprodução de comunidades negras, por isso, esses bairros tiveram uma construção cultural muito forte.

\section{PENSANDO A CIDADE FORA DO EIXO DE GRANDES PRODUÇÕES}

Quando penso em grandes centros urbanos, logo vem a imagem de sua materialidade: arranha-céus, grandes fluxos de informações, pessoas, aviões, trens, carros, multidões, congestionamentos, imensas infraestruturas, ruínas, poluição, a visível desigualdade espacial, o frenético ritmo da dinâmica da vida nos grandes centros. Essa representação das metrópoles é muito bem-exemplificada pelo experimento cinematográfico Koyaanisqatsi ${ }^{1}$, de Godfrey Reggio, que tem a intenção de mostrar o caos da vida nas cidades, como o próprio significado da palavra "Koyaanisqatsi" representa, na língua hopi: "vida maluca", "vida em turbilhão", "vida fora de equilíbrio". Simmel (2005), no final do século XIX, já havia chamado atenção para esse estilo de vida que começava a se desenhar nas metrópoles, aquilo que ele chamou de "intensificação da vida nervosa".

A noção de cidade e de vida urbana que foi se constituindo ao longo do tempo, é muito representativa do ponto de vista de como se pensa esse conceito, sempre ligado às multidões, prédios, "caoticidade" etc., mas também é válido notar a relação da cidade com o corpo, o corpo com o espaço (Sennett 2016), como a multidão, por exemplo, como sinônimo dos grandes centros. $\mathrm{Na}$ imagem do espaço urbano, o espaço torna-se um lugar de passagem, lugar de movimento, como no filme Koyaanisqatsi. O conceito de urbano ligado à cidade nasce de uma relação de pluralidade;

1 O filme Koyaanisqatsi: Life out of balance (1982) é o primeiro filme da trilogia Qatsi, que apresenta uma reflexão da ação do homem sobre a natureza, modificando, destruindo, implodindo, criando, produzindo em escala, o que traz uma sensação de competição com o tempo. 
pluralidade da capacidade de concepção e construção do espaço (Certeau 1998). Assim, pensar a cidade é pensar em sua multiplicidade de realidades que não se encaixam em padrões e conceitos tão gerais. Nessa perspectiva, a proposta desse artigo é fazer uma reflexão sobre essa diversidade a partir da análise de consolidação de dois bairros, Camboa e Liberdade, localizados no centro da capital São Luís. Logo, por que pensar a cidade a partir do estudo desses bairros?

Os estudos urbanos no Brasil inicialmente buscavam compreender as mudanças que estavam acontecendo com um país de origem colonial e que passava por um rápido processo de industrialização e urbanização. Os chamados "estudos de comunidade", linha importante de investigação das Ciências Sociais americana na década de 1920, constituíram-se como principal corrente de investigação entre os antropólogos e sociólogos brasileiros e forneceram as bases para as pesquisas sobre as mudanças sociais no país. Com isso, destacavam-se pesquisas sobre as religiões africanas, as populações negras e as situações de preconceito racial, os estudos sobre imigração estrangeira para o Sul e Sudeste do Brasil e estudos sobre folclore. Essas investigações pautavam-se em compreender essa sociedade que estava passando por diversas transformações em seu bojo, ou seja, em entender as bases no qual essa mudança estava operando (Durham 1980).

Atualmente, pensar os estudos urbanos e a produção do espaço na Sociologia e Antropologia brasileira é se deparar com uma tradição de pesquisas sobre violência, migração, política, sociabilidades etc., estudos que se concentraram nos grandes centros urbanos. Não é de se estranhar essa tradição, pois as investigações sobre o urbano nas Ciências Sociais se estabeleceram em entender o crescimento das grandes metrópoles. Assim como os estudos urbanos se concentraram em assuntos, como desigualdade espacial, violência, marginalidade etc., também tiveram como foco de pesquisa as cidades dos grandes centros urbanos do país, em especial do eixo Rio-São Paulo.

A produção de pesquisas nesse eixo muito se deu pelo fato de se estabelecerem como grandes centros de migração e imigração do país. O Rio de Janeiro, por ser a capital do Brasil colonial; e São Paulo por se constituir como grande polo de industrialização do país. Além disso, foram também nesses dois centros que se estabeleceram os primeiros programas de pós-graduação em Sociologia e a Antropologia, dando autonomia para essas áreas de investigação.

Nesse aspecto, as cidades de São Paulo e do Rio de Janeiro constituíram-se como polos de tradição dos estudos sobre cidades e o urbano. Em São Paulo destacavam-se as pesquisas sobre periferias 
e as formas de sociabilidade que influenciaram o urbano, redes de parentesco, vizinhança, modos de vida, representações políticas e simbólicas. No Rio de Janeiro, prevaleceram estudos mais estruturantes e generalizantes, como os de $\mathrm{Da}$ Matta, e análises de cunho mais etnográfico com Velho (Moneratt \&Vieira 2019).

O desenvolvimento dos estudos urbanos no Brasil, nesse sentido, se consolidou pela hierarquização desses centros como linhas de pesquisa. Estudos sobre violência, favelas, periferização, habitação etc. têm seu norte de análises nos eixos Rio-São Paulo. Houve avanços com a descentralização dessas pesquisas, decorrentes da expansão dos programas de pós-graduação por todo o país, principalmente na última década entre 2003 e 2016 com maior interiorização e dando fôlego à área de Ciências Sociais, como apontaram Moneratt e Vieira (2019).

Embora reconheça a importância desses centros como produção do conhecimento nos estudos urbanos e o crescimento e expansão de pesquisas em outras regiões do país, é ainda inegável a influência dos grandes eixos e a produção hierárquica de modos de saber sobre as cidades e o contexto urbano. Desse modo, chamo atenção para a necessidade de cada vez mais voltar as produções para as cidades que estão fora do eixo Centro-Sul e que possuem características singulares.
Voltando ao questionamento inicial, pensar a cidade de São Luís a partir do estudo de dois bairros é pensar a produção do conhecimento fora dos grandes eixos urbanos brasileiros, é pensar a cidade em sua singularidade que não se encaixa em conceitos, como "grandes centros urbanos", ou nos conceitos de "periferia", "favela", muito utilizados nos estudos urbanos das Ciências Sociais.

São Luís, por exemplo, é considerada uma metrópole, pois pelos padrões normativos que a caracterizam, ela possui mais de um milhão de habitantes. Ao mesmo tempo se constitui enquanto uma metrópole por numericamente apresentar um total "x" de habitantes, a cidade possui outras características peculiares que não a caracterizam como "grande metrópole". É uma cidade que não possui grandes arranha-céus, não possui um ritmo frenético de pessoas como nas grandes metrópoles, e que demandam horas de deslocamentos etc.; mas assemelha-se também nas desigualdades espaciais, na grande produção de poluentes, nos problemas de mobilidade.

Outras características a fazem uma cidade singular, pois possui um conjunto arquitetônico histórico intacto, com um título de patrimônio da humanidade; foi uma cidade bastante importante do período colonial e que teve um processo de industrialização anterior aos grandes centros. São Luís também se configura como local de resistência 
e reprodução de modos de vida de muitas famílias migrantes advindas dos territórios de Alcântara, em especial, nos bairros que se encontram na parte central da capital.

O objetivo desse artigo é fazer uma reflexão a respeito dos bairros da Camboa e da Liberdade. Eles são formados por muitas famílias migrantes que se consolidaram na relação entre ir e vir entre os territórios de Alcântara e São Luís (Cardoso 2008). Essa composição migratória está reproduzida nas sociabilidades culturais, econômicas e religiosas que compõem os bairros, considerados como um dos maiores quilombos urbanos do país.

As formas de moradia que caracterizavam os bairros eram as palafitas: casas de tábuas suspensas à beira do mangue. A composição geográfica dos bairros, ao lado do rio Anil, possibilitou a muitas famílias continuarem de certa forma, a reprodução de modo de vida camponês: nas atividades de pesca, na criação de pequenos animais. O mangue e o mar tornaram-se extensão de suas casas, e os bairros da Camboa e Liberdade tornaram-se extensão dos territórios negros de Alcântara e do litoral ocidental maranhense.

Nesse aspecto, analiso os bairros como locais de fronteira entre outros bairros que compõem aquele espaço e que simbolicamente são acionados por seus moradores. Também como locais de resistência, pela cultura e modos de sobrevivência reproduzidos ali. E, por fim, locais de adaptações, onde seus moradores vão adaptando suas moradias, suas atividades e sociabilidades frentes aos grandes projetos de urbanização.

\section{3 “TUDO AQUI ERA INVASÃO, TUDO AQUI ERA MANGUE": A FORMAÇÃO DOS BAIRROS CAMBOA E LIBERDADE}

Era uma tarde de quinta-feira, eu havia combinado com Daniel ${ }^{2}$ para que ele me levasse para conversar com algumas pessoas. Nesse dia, para minha surpresa, fomos para a rua dos Veleiros, uma rua que fica atrás do Residencial Camboa, local onde existe um pequeno porto que atracam os barcos, por isso, o nome. Caminhávamos pela rua enquanto ele me mostrava a pequena igreja que ele frequenta, fundada por seu irmão, que é pastor. Observo algumas pessoas conversando na porta. Meu interlocutor aponta para seu irmão e seu pai sentados na pracinha que foi construída com o projeto de reurbanização daquela área. Seu irmão Carlos está tecendo uma rede de pesca, chamada de espinhel. Nos aproximamos e vou reconhecendo aquele rosto que me pareceu familiar ao seu lado. Era "Galego", o pai de Daniel, que eu

2 Daniel (nome fictício) é um dos meus principais interlocutores. Ele é uma liderança no Residencial onde pesquiso e também uma pessoa muito conhecida no bairro da Camboa. Todos os nomes citados no texto são fictícios. 
havia entrevistado anos atrás, muito antes daquela praça existir.

A Camboa, assim como outros bairros incluídos no projeto PAC Rio Anil ${ }^{3}$, passou ao longo dos últimos anos por algumas mudanças. A rua dos Veleiros foi um dos primeiros locais de minha visita a campo e estava totalmente diferente do que encontrara anos atrás. Agora, o local contava com uma quadra de esportes, praça, equipamentos de ginástica, asfalto, cais reformado e os boxes para os pescadores. As colunas da ponte Bandeira Tribuzzi se destacavam pelo colorido dos grafites. A Camboa nem parecia mais aquela de antes, com lama do mangue, lixo. O local que costumava ser estigmatizado devido à presença de usuários de drogas que ficavam embaixo da ponte, um espaço também disputado por moradores de rua, carroceiros, pelas palafitas e o mangue que chegava ao asfalto.

Galego não é apenas o pai de Daniel, meu principal interlocutor, ele é um importante personagem da história do bairro, trabalhou a maior parte de sua vida como pescador e foi o primeiro morador da rua dos Veleiros, chegando no bairro ainda criança, acompanhando todo o processo de expansão do centro de São Luís, como o aterro de muitos locais que deram origem aos bairros, principalmente ao longo do rio Bacanga, o processo de aterro da área do Centro, o mar que deu espaço para avenidas ou os trilhos do bonde que deram espaço para o asfalto.

O bonde passava, eu sou da época
do bonde! A estação do bonde era
no Monte Castelo. Eu conheço todo
o trajeto do bonde, do trem aqui... Era
muito fundo aqui. Tubarão comia a
gente aqui, se caísse na água. Porque
tinha um Matadouro ali, tubarão
passava com a galha de fora. Isso aqui
era muito fundo! Naquela época tinha
muito peixe, muito tubarão, ninguém
saía pra fora pra pescar, pescava
era dentro do rio, peixe pedra tinha
demais, serra, anchova, logo não tinha
poluição nenhuma. (Galego, entrevista
em $16 / 1 / 19$ ).

Galego narra como era o vaivém do bonde que passava ali próximo, sempre lotado de gente. A Camboa na época em que chegou ainda tinha mata fechada e, segundo ele, era possível ver onça e outros bichos de caça. Para chegar ao bairro do São Francisco, do outro lado da vazão do mar, oposto ao Centro Histórico, só era possível atravessando de canoa, chamada por ele de "canoinha".

O pescador situa em sua narrativa todo o processo de expansão de São Luís, principalmente na área do Centro. A Camboa, bairro onde chegou criança, assim como a Liberdade, são bairros centenários e que possuem uma grande

3 O projeto PAC Rio Anil foi lançado em São Luís no ano de 2007 com o objetivo de reurbanizar áreas consideradas inadequadas para habitação, como também a remoção de moradores de palafitas e suas transferências para conjuntos residenciais construídos pelo projeto. O projeto construiu apartamentos de $42 \mathrm{~m}^{2}$ para os moradores retirados das palafitas, reurbanizou a área onde se encontravam as moradias e instalou equipamentos urbanos. 
especificidade de sua ocupação desde a fundação da Fábrica de Fiação e Tecido e o Matadouro, que deram origem aos bairros, até no modo de vida de suas populações, em sua maioria, migrantes de outras regiões do estado.

Desde os primeiros registros de habitações insalubres em 1920, há menção ao bairro da “Camboa do Mato". De acordo com o dicionário Aurélio (1998:120), o nome Camboa significa um “estreito por onde a água penetra, na maré alta, e que esvazia quando as águas refluem na baixa-mar; Gamboa”. Essa definição indica as características do local, uma vez que a região é local de vazante do rio Anil.

Etimologicamente, segundo Curvelo-Matos (2014: 86), camboa/gamboa significa "cercado de traqueias ou fecho de paus e cipós, ou seja, uma armadilha para pegar peixe ou técnica muito usada pelos tupinambás para pescar, que foi herdada pelo maranhense". Essa definição para a autora é mais uma evidência de que a localidade da Camboa era habitada por indígenas, daí a origem do seu nome, e não por causa da fábrica que se instalara ali. Em síntese, Curvelo-Matos (2014) observa que o a origem da palavra resgata os hábitos de pesca dos tupinambá que viviam na área do centro da capital, o que comprova sua tese de que não houve alteração em relação à denominação do local.
Apesar de não ser citada nas primeiras descrições sobre as aldeias listadas em São Luís, quando a Fábrica de Fiação e Tecidos se instalou na Camboa, o lugar já existia com a denominação. As notícias que remontam ao final do século XIX relacionam o bairro aos operários da fábrica ali existente, a Fábrica de Fiação e Tecidos Camboa. A ocupação da Camboa vai estar relacionada à instalação da fábrica de tecidos que se fixou próxima à baía de São Marcos, a pouco mais de $4 \mathrm{~km}$ do perímetro urbano na época, além de estar situada às margens do rio Anil, fatores que facilitariam o transporte das matérias-primas (Ribeiro Júnior 2001). Além do mais, a instalação da fábrica acabou forçando o seu operariado a alojar-se ali próximo, pois, inicialmente, era mais vantajoso manter os trabalhadores perto das fábricas, economizando assim no transporte e facilitando a sua assiduidade.

Além da proximidade do rio ter propiciado a instalação da fábrica da Camboa, em 1921, a instalação da Estrada de Ferro São Luís-Teresina (EFSLT) também vai contribuir como alternativa para o escoamento da produção de mercadorias (Ribeiro Júnior 2001). A estrada de ferro passava no que hoje é a avenida Camboa, principal via que perpassa os bairros aqui analisados, o que também colaborou para o seu povoamento. 
Companaia dle Fhagho e Teel-
stos Maranluense.

De ordeun da Directoria faz-se p'llicu que recebem se propostas $\mathrm{em}$ artas lechadas; no escriptorio da Companhia, até ás duas horas da tarue ac dia 27 do corrente, quando serăo aber. tas en presenca dos proponentes, par: fornecimento de tóros de mangue vermellin

0 fornecimento serà de 25 mil tỏro: por mez, durante seis mezes a conta de $1 .^{\circ}$ de Julbo vindouro, os quae. serão recebidos no porto da Cambô do Matto, tendo os tóros 80 á 88 cen timetros de comprimento e 11 a 1 de diametro.

Maranhāo 17 de Janho de $\mathbf{1 8 9 1 .}$

Manoel $J$. d'Azevedo Almeida Director Secretario.

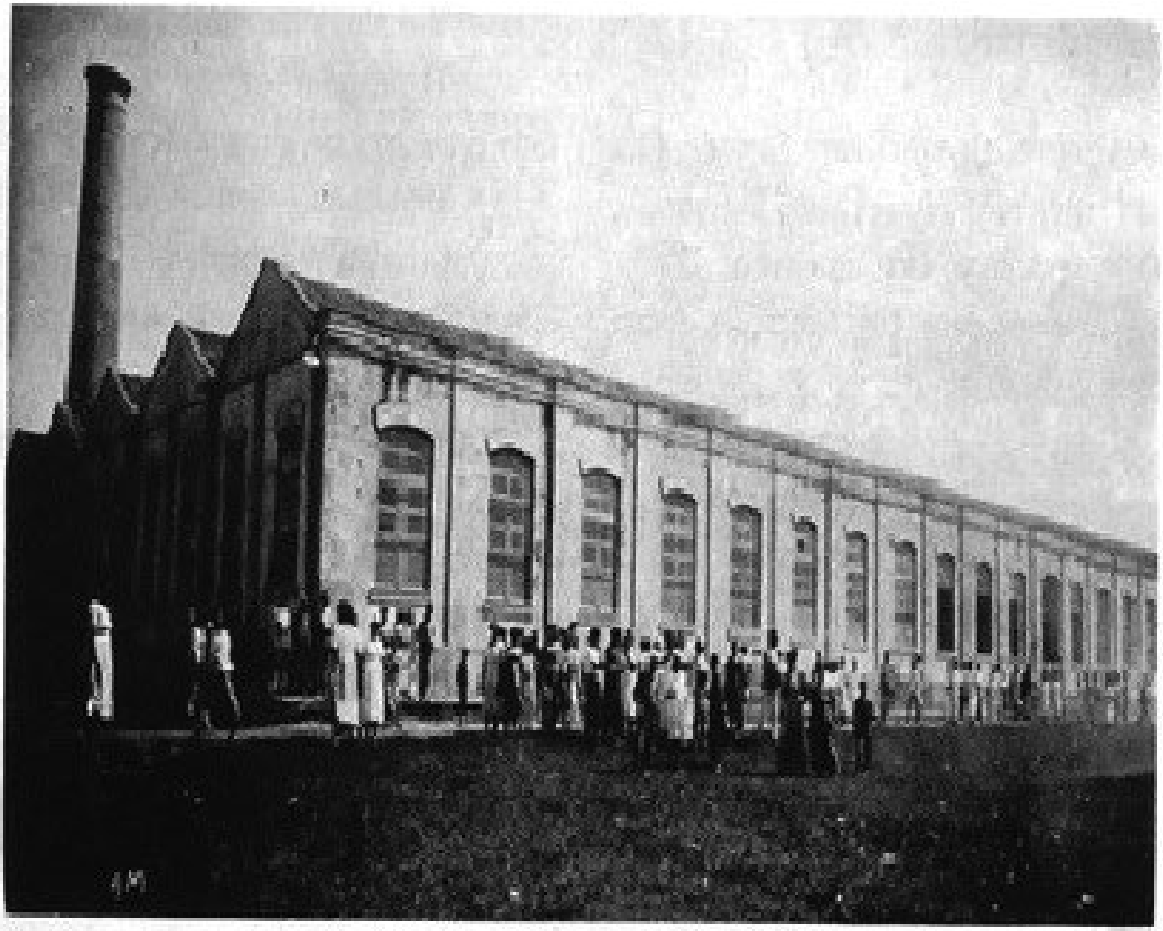

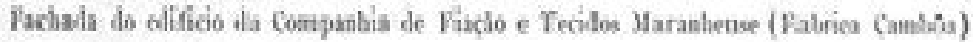

Figura 1 - Nota sobre a Cia. de Fiação e Tecidos Maranhense e foto do edifício da Fábrica.

Fonte: A Cruzada (1891) e Maranhão (1923).

Sobre o bairro da Liberdade, Silva (1997) aponta que sua origem ocorreu em razão da construção do Matadouro Modelo de São Luís, que foi instituído pela Lei Municipal no 260, no ano de 1918, onde o terreno para a sua construção seria localizado em local de fácil acesso, ou seja, próximo ao rio, como também priorizando a estrada de ferro que estava em construção. $\mathrm{O}$ bairro denominado Matadouro era até então constituído de um pequeno povoado. Para o autor, o povoamento da área se deu em razão da ocupação de terras próximas ao Matadouro, que aconteceu tanto pela busca de moradia e proximidade do centro urbano, quanto pela facilidade em se conseguir carnes nos arredores do local. Com isso, as áreas do Matadouro foram cada vez mais sendo ocupadas, até que, com o encerramento do contrato com a Prefeitura em 1937, muitos terrenos foram invadidos, pois o Matadouro e suas terras anexas passaram a ser de controle do município. 


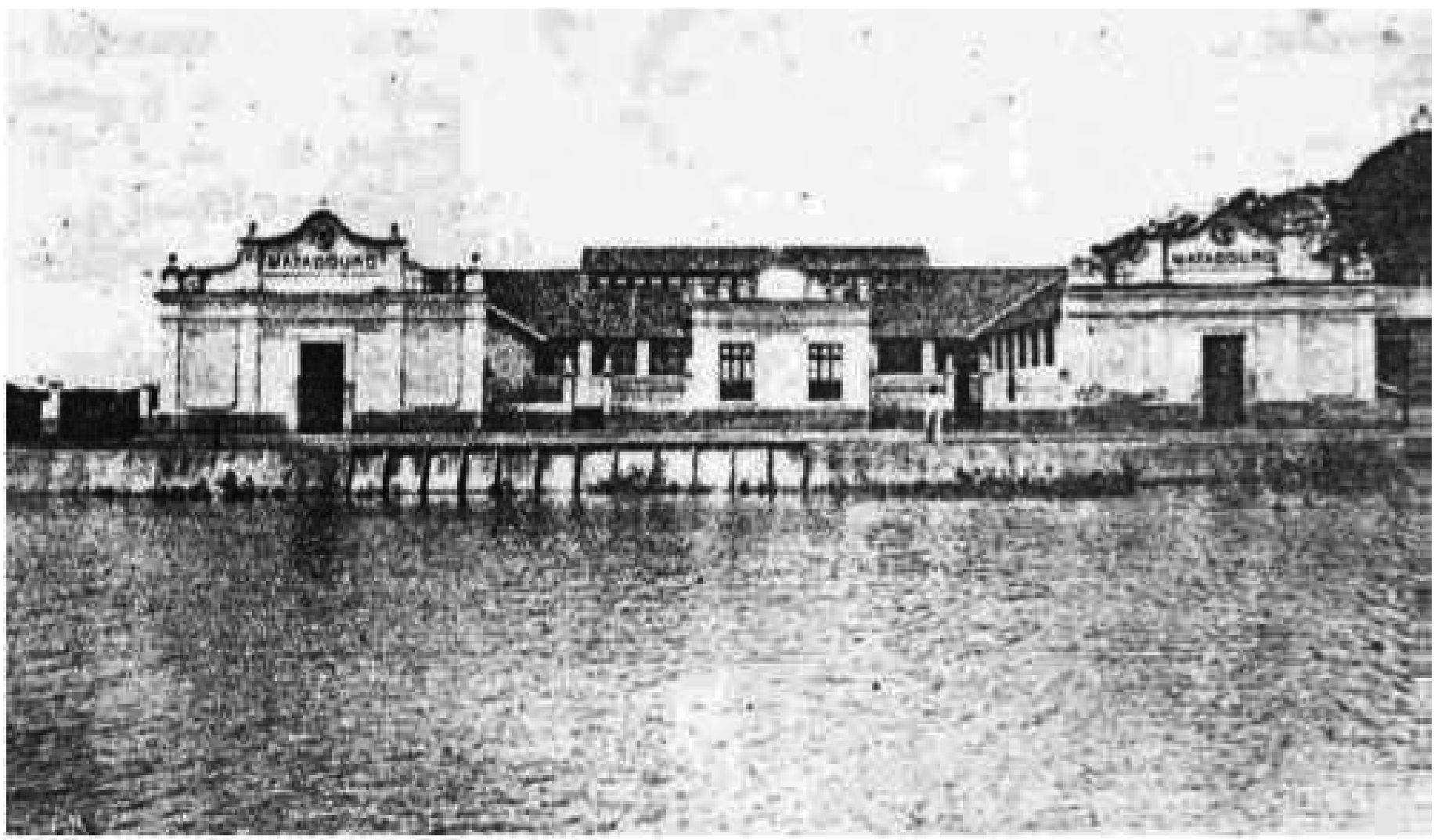

Figura 2 - Matadouro Modelo. Fonte: Maranhão (1923).

Em relação ao adensamento destes bairros, Burnett e Silva (2014) destacam que fatores como a perda da cidade de São Luís como centro exportador a partir da década de 1930, juntamente com o intenso êxodo rural decorrente dos conflitos no campo, foram fundamentais para a ocupação de grandes áreas da região. A composição social desses novos habitantes pode ser caracterizada por um grande percentual de migrantes do interior do estado. Sendo assim, as áreas onde se encontram os bairros Camboa e Liberdade possuem um histórico de concentração de habitações do tipo palafitas. Segundo Silva (1997), a formação do bairro da Liberdade data então de 1950 em diante, com o processo de ocupação e migração de muitas famílias dos municípios oriundos da Baixada Maranhense.

As palafitas são, nesses bairros, o maior exemplo de moradia precária das populações que passaram a ocupar as áreas próximas à Fábrica de Tecidos como também o Matadouro, depois com os intensos fluxos migratórios de famílias vindas de outros municípios do interior do estado. 
Muitos terrenos próximos ao antigo Matadouro foram ocupados ou doados pela Prefeitura, o que facilitou o acesso à moradia e o adensamento do bairro da Liberdade. No que diz respeito ao bairro da Camboa, observa-se que ainda existe uma grande área de mangue tomando quase toda a extensão do bairro indo no sentido do antigo Matadouro.

Apesar de existentes, as palafitas são quase imperceptíveis na paisagem urbana de São Luís naquele momento, sendo localizadas bem próximas às áreas inacessíveis de mangue. É com o fim das atividades industriais, na década de 1960, e um intenso fluxo migratório entre as décadas de 1970 a 1990 que a ocupação das áreas de mangue vai se intensificar, resultando em muitas áreas de mangue derrubadas para a construção de moradias.

Atualmente, os bairros da Camboa e da Liberdade possuem uma característica bem peculiar: além dos fatores que levaram ao povoamentos dessas áreas, já destacados anteriormente, há outros fatores, como o forte relacionamento entre a cidade de Alcântara e esses bairros. Segundo Cardoso (2008 apud Luz Silva 2007), a fixação entre as famílias de diferentes povoados alcantarenses, em São Luís, vai se concentrar, em especial, nesses dois bairros. Há, também, as migrações decorrentes dos conflitos territoriais existentes com a implantação do Centro de Lançamento de Alcântara, hoje intitulado
Alcântara Cyclone Space, projeto que se iniciou na década de 1980 e até hoje causa migrações dessas populações para essas áreas (Burnett \& Silva 2014).

Cardoso (2008) ressalta que as características que essas áreas reúnem, como o acesso facilitado a terrenos (por serem áreas alagadas e desvalorizadas), a existência de vários atracadouros que possuem ligação direta com outros portos de Alcântara, são fatores que fazem com que muitas famílias desses territórios acabem migrando para os bairros.

Esse fácil acesso ao mar e aos portos dos municípios de Alcântara contribui para as atividades de pesca nessas áreas, concentrando um grande número de pescadores. Na verdade, a atividade de pesca é algo que sempre existiu na Camboa, como Curvelo-Matos (2014) apontou ao analisar a etimologia da palavra em relação à prática de pesca dos tupinambá.

Além disso, esse "vaivém" entres os municípios e a capital propiciou as atividades econômicas nos bairros, principalmente no bairro da Camboa, onde pode-se encontrar a venda de carvão, da madeira que é utilizada na confecção de palafitas, do peixe que é comercializado nas feiras locais, entre outras matérias-primas e produtos advindos dos municípios de Alcântara ou da Baixada Maranhense. 


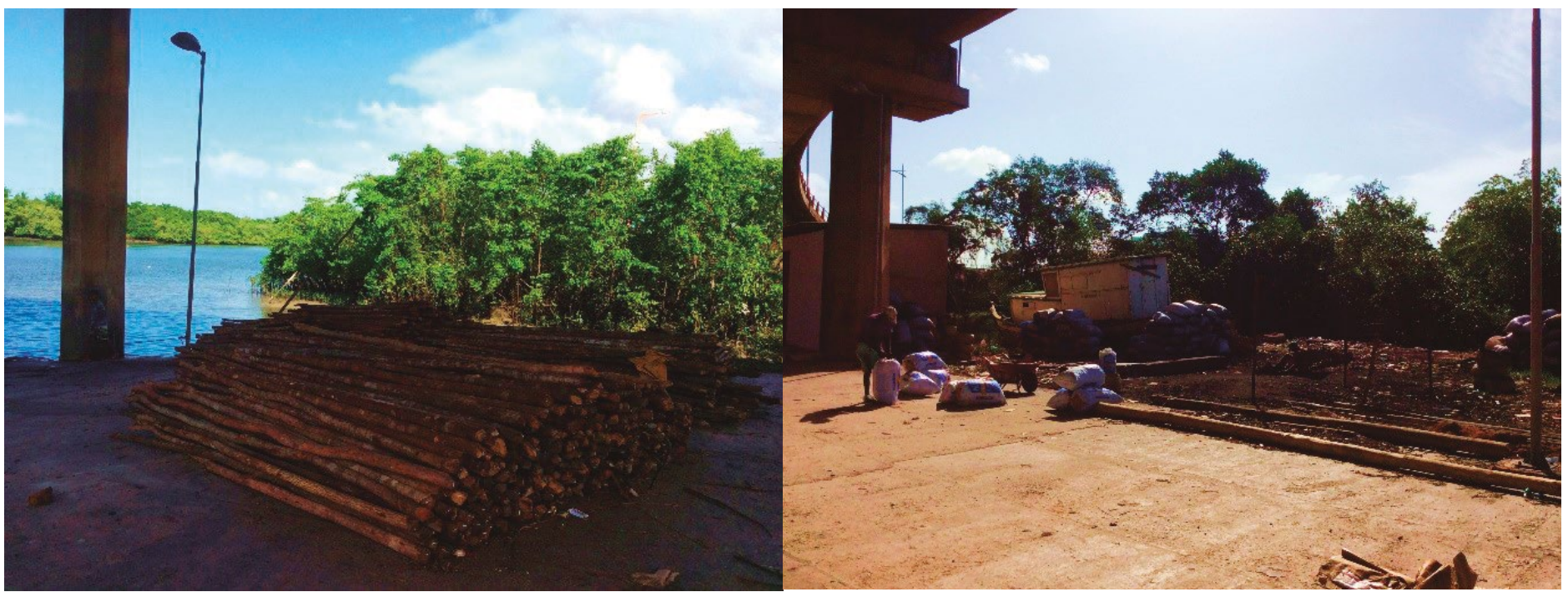

Figura 3 - Madeira e carvão que chegam ao cais da Camboa para serem comercializados.

Fotos: Maysa Oliveira, 2017.

Outros fatores também observados por Cardoso (2008) contribuem para a escolha desses bairros como destinos de muitas famílias migrantes, como as relações de parentesco, ou seja, muitas famílias acabam migrando e morando com parentes já residentes nessas áreas também em razão da proximidade com o Centro da cidade, da busca por emprego e de melhores escolas para os filhos. Nessa lógica, muitas famílias migrantes vão ocupar empregos, como empregadas domésticas, pescadores, vigilantes, ambulantes, feirantes, carroceiros etc., atividades que requerem pouca especialização.

Além desses aspectos, esses bairros são reconhecidos pela existência de um grande número de manifestações culturais e também pelo seu histórico movimento de luta pela moradia nos anos 1980, fazendo, em especial, do bairro da Liberdade, o lócus do surgimento da Associação dos Moradores Palafitados do Bairro da Liberdade (AMPBL), que teve grande importância no movimento pela moradia naquele período.

Em 2014, como parte do projeto do PAC Rio Anil, foi realizado um estudo sobre os bairros incluidos no projeto de reubanização, cujo resultado é um mapa cultural das comunidades localizadas na área de abrangência do projeto. Foram catalogadas 87 organizações culturais e religiosas, nos quais incluem: bumba-meu-boi, tambor de crioula, capoeira, blocos tradicionais, festejo do Divino Espírito Santo, terreiros, quadrilhas, cacuriá, danças, associações e conselhos etc. 
volume $13(2)$ | 505 - $530 \mid 2021$

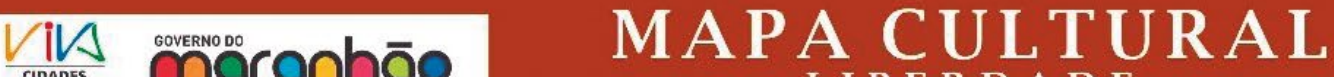
L I B E R D A D E

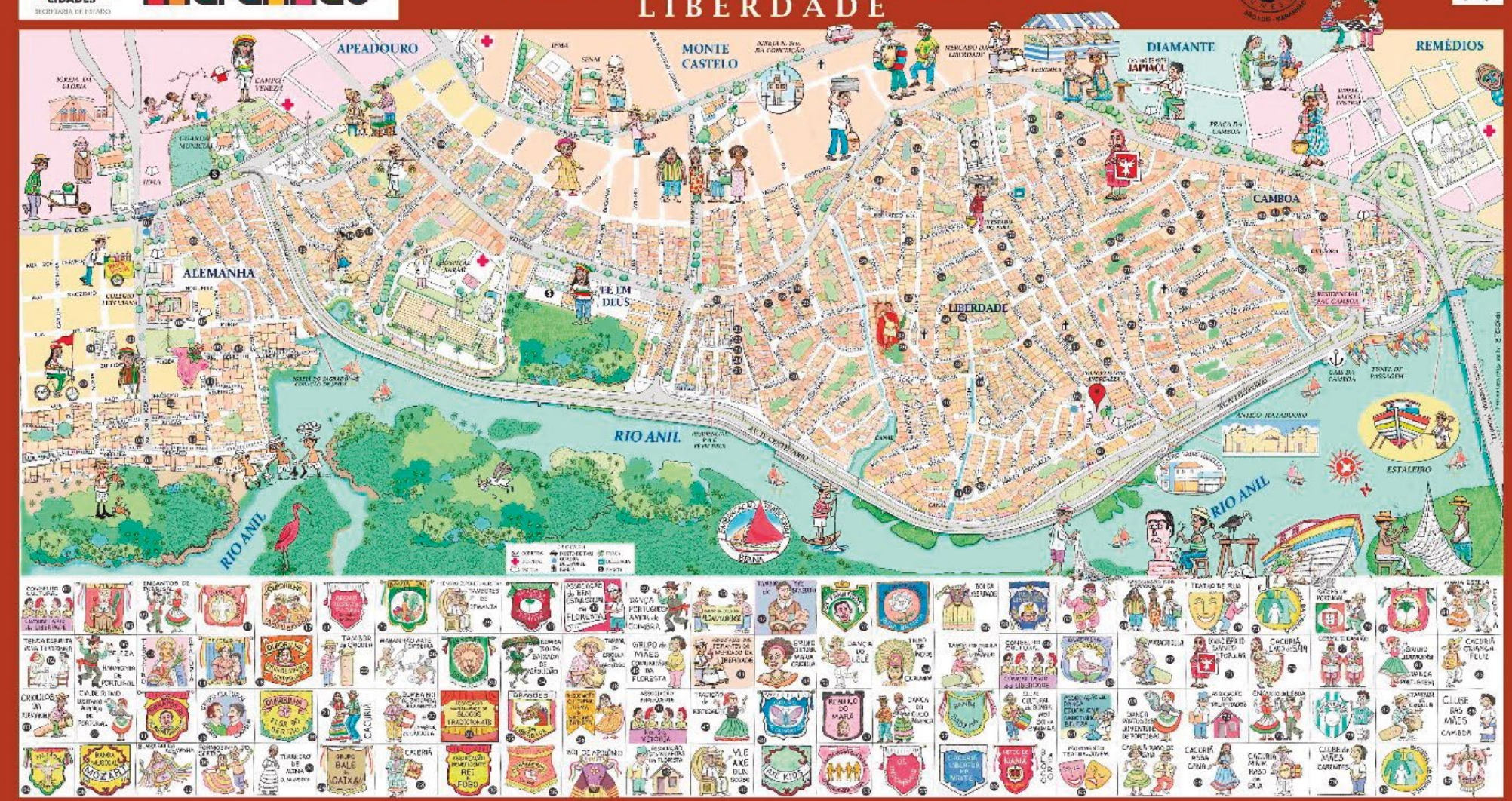

Figura 4 - Mapa Cultural da Liberdade. Fonte: Secretaria das Cidades (2015).

Apesar dessas características singulares de sua diversidade cultural, esses bairros são demarcados como locais violentos e seus moradores são constantemente estigmatizados, já que os dois locais são considerados, pela opinião pública ludovicense, como os mais violentos da cidade.

Essa estigmatização pode ser relacionada desde a fundação dos bairros, que foram ocupados por proletários e migrantes que encontraram em terrenos mais baratos e acessíveis uma oportunidade de moradia, sendo em casebres de palha, ou nas palafitas, morando na lama, ou próximos aos despejos do matadouro. Sobre isso, Caldeira (2000) destaca que existe uma associação dos espaços periféricos com o crime, principalmente as favelas, sendo que nelas as casas são construídas ilegalmente, não pagam impostos municipais, não têm endereço oficial, o que denota que seus moradores vivem na ilegalidade e não são considerados cidadãos. Essa ilegalidade, de acordo 
com a autora, faz com que esses moradores sejam "excluídos do universo do que é adequado, eles são simbolicamente constituídos como espaços do crime, espaços de características impróprias, poluidoras e perigosas” (Caldeira 2000:80).

Apesar de consideradas como habitações precárias e ilegais e que não estão de acordo com os padrões dos órgãos legisladores, as palafitas são um tipo de habitação que possui técnicas tradicionais, saberes que demandam uma relação com a natureza e o espaço. Além disso, se estabeleceram e estabelecem na realidade ludovicense como o meio mais fácil de acesso à moradia por muitas famílias migrantes.

\section{FRONTEIRAS QUE DESAPARECEM: OS BAIRROS DA CAMBOA E LIBERDADE COMO TERRITÓRIOS ALCANTARENSES}

Pensar a continuidade dos territórios de Alcântara e Baixada Maranhense em bairros de São Luís não é algo novo. Cardoso (2008) apresentou essa tese em seu estudo de caso com uma família residente no bairro da Camboa e advinda de Alcântara. Outro trabalho, o artigo de Godoi e Pina-Cabral (2014), discute que as relações de obrigações mútuas entre vizinhos e parentes não se desarticulam quando esses camponeses se transformam em trabalhadores nas grandes metrópoles. Essas relações, na análise dos autores, se expandem para além dos povoados de Alcântara, chegando a São Luís e a São Paulo. Já o trabalho de Assunção (2017) foi peça fundamental para que esses bairros fossem reconhecidos como quilombo.

Durante minha pesquisa de mestrado, ao tentar traçar o perfil dos moradores do Residencial Camboa a respeito de suas trajetórias e antigas moradias $^{4}$, percebi que muitas famílias vinham de povoados de Alcântara ou de cidades do litoral ocidental ou da Baixada Maranhense. A facilidade de acesso à moradia naquelas localidades, por se constituírem em áreas de mangue, fez com que muitas famílias se estabelecessem ali, e utilizassem o rio para atividades de pesca e coleta e mariscos. Além disso, por estar localizado no centro da cidade, próximo a escolas, hospitais e outros serviços, muitas famílias fixaram-se ali.

Outro fator bastante importante é a rede de apoio de familiares que já moravam nesses bairros e que acabam dando suporte aos demais. Isso foi perceptível quando, em meus questionários, percebi que famílias inteiras praticamente moravam na mesma rua, ou quando nas entrevistas, os moradores me contavam como chegaram ao bairro,

4 A pesquisa no mestrado buscava compreender o processo de socialização dos moradores do Residencial construído pelo PAC. Muitas famílias dos bairros da Camboa, Liberdade e Fé em Deus foram transferidas de palafitas para apartamentos. Os bairros, por sua vez, passaram por diversas intervenções urbanas. 
sempre por meio de um parente, irmão, tio, primo que já morava ali.

Em sua pesquisa, Luz Silva (2007) aponta os bairros da Camboa e da Liberdade como locais onde se concentram um grande número de pessoas oriundas do município de Alcântara. Esse agrupamento de famílias nas mesmas ruas e bairros vão possibilitar a reprodução de modos de vida nessas localidades, expressos nas brincadeiras culturais, na religiosidade e nas festividades, como destaca Cardoso (2008):

\begin{abstract}
Um dos indicativos dessa agrupação com base em elementos de caráter étnico é o fato de os alcantarenses, oriundos de povoados, se reunirem em ruas e bairros específicos na cidade de São Luís, formando bairros inteiros e depois constituindo grupos de bumba meu boi, promovendo festas de santo, encontrando-se nos terreiros de mina, juntando-se nas feiras livres para vender o pescado. Ou seja, há toda uma recriação/permanência do universo camponês de Alcântara e de toda a Baixada Maranhense na capital. A escolha do local para residência, [...] está ligada ao fácil acesso a essas áreas de mangues para moradia. Percebese, porém, que a solidariedade dos parentes e conhecidos do interior foram determinantes para sua escolha, principalmente no tocante à cessão de uma casa [...] (Cardoso 2008: 59)
\end{abstract}

A procedência desses migrantes diz muito sobre suas relações com o espaço, uma vez que, em suas cidades de origem, muitos tinham como meio de sobrevivência o trabalho no campo e na pesca. A localização estratégica dos portos permitia o fluxo comercial entre feiras, mercados e fábricas de tecido e também a chegada de mercadorias e de pessoas de diversos povoados (Cardoso 2008). A proximidade com os portos e o mar foi primordial para a instalação da Fábrica de Tecido, na Camboa, e do Matadouro Modelo, na Liberdade, duas importantes atividades que contribuíram para a consolidação dos bairros. Até hoje, o portinho da Camboa possui uma relação importante para os moradores da localidade, que encontram na atividade de pesca uma forma de sobrevivência, de lazer, e também uma ligação com outros territórios.

Ao migrarem para o centro urbano, essas populações vão ocupar-se em atividades, como vigias, empregadas domésticas, trabalhadores da construção civil, donos de pequenas vendas, eletricistas e carroceiros (Pereira 2010). Ou quando não, pescadores, já que a proximidade do rio facilita a atividade da pesca que, muitas vezes, também se torna uma atividade secundária.

Para Cardoso (2008), o rio tem uma importância na composição das habitações dessas famílias, pois elas o entendem como uma extensão da casa e que as permitem manter os laços de identidade com suas origens.

[...] A beira do igarapé, por meio de seu acesso, o portinho, como o lugar de trabalho árduo, intenso, se confunde com a rua, tanto lugar do lazer, da ociosidade, tanto quanto do trabalho, transformando-se mesmo em extensão da própria casa ("é o quintal da minha casa”). Não há, inclusive, aqui, oposição entre casa e lugar de trabalho, pois o igarapé é uma extensão da própria casa, como seu quintal. Haveria, 
digamos assim, uma promiscuidade entre espaços físicos - casa, rua, igarapé - permitindo que a família se realize na cidade, uma vez que seu chefe pode exercer a atividade de pescador muito praticamente dentro de casa e comerciá-lo muito próximo dela. Neste caso, a família teria conseguido juntar local de trabalho e local de residência num só espaço físico, sem perder seus laços de identidade com o grupo de origem, sem romper com as fronteiras étnicas que a vincula ao povoado Santana, onde tem garantido um lugar. (Cardoso 2008:63)

Por serem provenientes de regiões que têm ligações com o rio ou o igarapé, e trabalharem em atividades de subsistência, como a roça, muitas dessas famílias da Camboa e da Liberdade veem nesse espaço a oportunidade de conseguir garantir sua sobrevivência no meio urbano, seja na pesca, ou na coleta de mariscos e moluscos, passando o mar e o rio a serem substitutos da terra, no que corresponde em prover a alimentação e renda das famílias. Cardoso (2008) aponta que a migração ou o deslocamento para o centro urbano ao invés de contribuir para uma descaracterização cultural do universo camponês, neste caso, permitiu reforçar essa identidade, dada as condições ecológicas que o próprio bairro ou a cidade ofereceram. As "favelas" na beira da maré, como são denominadas as palafitas, seriam, nesse caso, uma extensão da vida camponesa dessas famílias originárias dos povoados e pequenas cidades do litoral e Baixada Maranhense.

\section{DE "CASAS DE PALITO" AO PROCESSO DE "ENTULHAMENTO": AOS POUCOS, A COMPOSIÇÃO DE DOIS BAIRROS}

Na composição dos bairros da Camboa e da Liberdade, dois elementos não devem deixar de ser pontuados: as habitações palafitas, que são expressivas na constituição dos bairros, chamadas pelos moradores de "casas de palito" ou de "favelas"; e o processo de "entulhamento" dessas áreas, que propiciou o processo de aterro dos bairros.

Denominada popularmente como "casa de palito", casa de "pernas de pau”, a palafita é considerada um tipo de moradia "precária" classificada pelo Ibge (2019) como "aglomerado subnormal”, ou seja, identificada dentro dos padrões urbanísticos como um tipo de ocupação irregular, com carência de serviços, como distribuição de água, esgoto, coleta de lixo, dentre outras infraestruturas.

Embora em termos práticos, as palafitas estabeleceram-se estrategicamente na paisagem urbana de São Luís como única possibilidade de acesso à habitação e forma de ocupação da terra por muitas famílias migrantes. Mesmo sendo considerado "precária" por padrões de classificação, esse tipo de habitação possui uma técnica específica de construção, além de ser uma forma de habitação já usada por povos no período 
pré-histórico e fora encontrada em regiões da Baixada Maranhense ${ }^{5}$.

Nos escritos de Raimundo Lopes, na obra intitulada A Civilização Lacustre(1924), as palafitas são mencionadas pelo geógrafo em um percurso sobre a origem dessas formas de habitação, chamadas também de "estearias". As estearias, que correspondem à palavra italiana palafitta, para designar as cidades lacustres europeias, são descritas por Lopes como registros de uma civilização indígena no Brasil, que ocupou rios e lagos do Cajary, Pindaré e Penalva, regiões da Baixada Maranhense.

A documentação do autor sobre essas formas de habitação destaca um modo de habitar ligado à vida de pescadores e vaqueiros dessas regiões. $\mathrm{O}$ que significa dizer que, para além de apenas uma forma precária de habitação que as populações mais pobres encontram como meio de acesso à moradia, as palafitas têm um histórico comum na vida dessas pessoas.

De origem indígena, esse tipo de habitação é muito presente na região amazônica e adotada por ribeirinhos. De acordo com Menezes, Perdigão e Pratschke (2015), a palafita caracteriza um padrão espacial descrito pelo sistema mata-rio-roça- quintal. Esse padrão se encontra nas margens de igarapés, rios e furos ${ }^{6}$.

Da cultura indígena, o tipo palafita
absorve relações de proximidade
e de continuidade com a natureza,
principalmente com o rio e com
espaços de várzea, evidente na
maneira como o ribeirinho habita
ao estabelecer sua casa em cima
da água, como tira seu sustento
através da pesca e como transita
diariamente. A floresta e o rio agem
como uma extensão da casa, o que gera
uma relação de sucessão entre esses
espaços, muitas vezes a partir de um
jirau na cozinha que tem vista para
um quintal, atuando como espaço de
transição entre a casa e a floresta ou o
rio, conforme descrito pelo sistema mata-
rio-roça-quintal (Menezes, Perdigão \&
Pratschke 2015:242 [grifo nosso]).

Por esse ângulo, fica evidente a relação da palafita com os aspectos externos da natureza. $\mathrm{O}$ rio como uma extensão da casa, local de circulação dos barcos e meio de sobrevivência. Essa relação com o espaço também pode mudar entre o meio urbano e o rural, como destacam as autoras:

Na produção informal do tipo
palafita em áreas rurais, observa-
se que as relações mencionadas se
encontram estreitamente vinculadas
ao meio natural, mantendo maior
distância entre as casas e preservando
deslocamento pelo rio. Em áreas
urbanas, a limitação no acesso à terra
e a busca por uma localização próxima
aos centros comerciais comprometem a
reprodução do sistema e o contato com
o ambiente natural, observando-se um
menor distanciamento entre as casas.
[...] (Menezes, Perdigão \& Pratschke
2015:243).

5 Ver mais em: Navarro (2017).

6 Furo, na região amazônica, é o nome dado a um espaço navegável que corre entre as árvores e serve de comunicação entre dois rios. 
As palafitas que caracterizam os espaços periféricos da capital São Luís vão aglomerar-se nas margens de rios, pois são nesses locais que o "acesso a terra" torna-se mais fácil por serem áreas desvalorizadas. Além disso, essa proximidade com a natureza também propiciará o meio de sobrevivência dessas populações por meio da pesca, do transporte de produtos, na coleta de mariscos etc.

No caso dos bairros que circundam o rio Anil, os diversos conjuntos de palafitas eram denominados por seus moradores de "favela". O conceito de "favela", "periferia" muito utilizado nos estudos urbanos no eixo Rio-São Paulo não pode ser entendido da mesma forma para os estudos em cidades do Nordeste/Norte, por exemplo. Nesses lugares, esses espaços possuem outras dimensões, perspectivas e sentidos. "Favela" no contexto do meu objeto de estudo, por exemplo, é utilizado para denominar as palafitas onde as famílias que habitavam as margens do rio Anil denominavam seus antigos locais de moradia. As "favelas" eram pequenas vielas de palafitas que compunham aquele espaço. Nesse caso, nos bairros da Camboa e Liberdade existiam várias favelas: "favela do Maruim", "favela do Mangue Seco", "favela dos Veleiros", "favela da Camboa". As "favelas" nesta pesquisa têm um significado muito específico.
As palafitas são construídas pelo processo de autoconstrução, por meio de mutirões ou, às vezes, pelo pagamento de terceiros. As técnicas utilizadas para a construção dessas moradias requerem o conhecimento do espaço e da natureza, uma vez que as palafitas são construídas em áreas alagadas.

Uma moradora do Residencial Camboa, Léia, em uma de nossas conversas relatou como é realizado o processo de fabricação da palafita. Nascida no município de Alcântara, mudou-se ainda adolescente para São Luís para trabalhar como doméstica. Esposa de pescador, ela morou por anos em uma palafita na Camboa, até mudar-se para o Residencial construído pelo PAC:

[...] dentro de um manguezal, aí você
roça aqui, né? Faz aquela derrubada,
destrói o mangue, né? [...] Daí você
já vai pegando as madeiras, já vai
fincando aqui, aí já bota a travessa, faz
um quadrado tipo uma mesa, daí você
já bota o assoalho, daí sobe as paredes
e já bota a telha. Aí outro chega e já
olha: “Rapaz tem um barraco aqui...” Aí
vem o nome de invasão, né? Aí chega,
e sucessivamente... Quando você vai
prestar atenção, já tá aquele correio
de casa desordenado e o mangue já
sumindo (Léia, entrevista em 16/2/16).

A moradora destaca também que, para fazer essa armação da palafita que ela chama de "mesa", é necessário fincar as bases de madeira três metros abaixo do mangue, para poder firmar a armação e manter uma distância entre a água da maré e o assoalho da casa. Esse procedimento é usualmente feito com uma madeira chamada 
"mangue vermelho", pois segundo a moradora, a lama do mangue ajuda a conservar a madeira por mais tempo. O piso das casas geralmente é de assoalho, feito com tábuas pregadas na armação, ficando com a aparência da "mesa", sendo depois erguidas as paredes e coberto o teto.

No que corresponde à estrutura interna da palafita, ela geralmente tem uma planta como um corredor, sem aberturas nas laterais, às vezes, com uma porta e uma janela na frente ou apenas só com uma porta. Nos fundos fica a cozinha, que por meio de uma pequena abertura, chamada “jirau”, são lavadas as louças, como descrevem Silva e Kapp (2016):

Uma vez que as palafitas costumam ser
construídas em linha, não há aberturas
nas fachadas laterais. Nos fundos, onde
se situa a cozinha, pode existir um tipo
de abertura conhecido como jirau, uma
espécie de bancada que se prolonga do
lado de fora, permitindo que a água da
lavagem de alimentos ou utensílios
caia diretamente no canal. (Silva \&
Kapp 2016:8).

Por ser construída em linha, geralmente as divisórias dos cômodos são feitos pelas placas de madeirite apenas de um lado da casa, deixando um corredor que vai direto para a cozinha. $\mathrm{Na}$ parte externa fica o banheiro, geralmente um cômodo à parte feito também de tábuas e sem cobertura. As casas não têm vaso sanitário, tudo é despejado para fora do cômodo. O acesso a essa parte é feito através de pequenas passarelas que tanto conduzem para o fundo das palafitas como também ligam umas às outras, fazendo uma espécie de "viela". Elas também fazem a ligação com ancoradouros de pequenos barcos chamados de "cascos", que geralmente atracam no fundo das casas. A iluminação das casas é clandestina, popularmente chamadas de "gato" ou "gambiarra"; não possuem água encanada, tendo os moradores que se deslocarem entre as "vielas" com baldes de água, ou comprar para o consumo próprio.

Com o passar dos anos, as palafitas tendem a passar pelo processo de aterro, mais conhecido como "entulho". Os moradores organizam-se em mutirões e pagam o transporte em caçambas de entulhos que muitas vezes são doadas, aterrando a parte da frente de suas casas, ficando os fundos ainda suspensos pela estrutura da palafita, para ancorar os barcos e escorrer seu esgoto.

Muitas casas na Camboa e na Liberdade, que hoje são de alvenaria, sofreram esse processo de entulho. "Entulhar" é o termo usado pelos moradores ao invés de aterrar, e é algo muito específico dos moradores desses bairros. O processo de "entulhamento" acontecia de forma coletiva e se dava primeiramente pelas vias e depois se expandia para as frentes das casas, que assim ganhavam uma fachada (Silva \& Kapp 2016).

Galego relatou em uma de nossas conversas no início de minha pesquisa na Camboa, como 
foi o processo de entulho de sua casa, trabalho que ele se orgulha de dizer que fez sem nenhuma ajuda do governo:

\begin{abstract}
Isso aqui foi eu que fiz. Isso aqui, depois que eles fizeram esse serviço da ponte, eu peguei o resto do material [...] aquelas sobras [...] é entulho, mas eles dão um nomezinho pra esse material de areia misturado com cimento [...] eu trouxe e aterrei aqui. Olha aqui, esses alicerces aqui, quando eu fiz ele, que eles têm um metro, um metro e pouco pra baixo, eles davam da terra pra cima, da onde ele era, eles davam um homem de mão pra cima. Você olhava pra minha casa era atrepado assim Aí foi entulhando... Isso aqui era só água, só esgoto...Eu fui fazendo as caixas, ajeitando...(Galego, entrevista em 20/2/15).
\end{abstract}

A rua dos Veleiros antes das obras de reurbanização do PAC já era totalmente aterrada. As palafitas que ainda restavam na rua, foram derrubadas e seus moradores transferidos para os apartamentos do programa PAC Rio Anil. A movimentação de barcos que ancoravam próximos à casa de Galego diminuiu, pois, segundo o morador, a extensão da avenida IV Centenário, construída com a finalidade de impedir novas construções de palafitas, tem impossibilitado a passagem de alguns barcos, inclusive do seu, que tem que se deslocar para a Ponta d'Areia para poder embarcar. Uma de suas queixas em relação ao PAC seria a construção de uma rampa flutuante para os barcos atracarem, o que não foi realizado. Moradora da Vila Gorete ${ }^{7}$ desde 1971, Dona Albertina, também descreveu como era a antiga rua quando chegou. De acordo com ela, a maior parte da rua era só mangue, tinha apenas uma grota e poucas casas, onde era necessário andar pelas calçadas para poder trafegar:

Era um cinzeiro ${ }^{8}$ do lado de lá, aqui era só mangue, aí aqui foi invasão. Tudo aqui era invasão. Tudo era mangue [...] Aqui também era mangue?

Tudo era mangue.... Essa casa aqui, está nesse comprimento porque quando a draga veio entulhar o mangue [...] Era palafita?

Era palafitada. Aí eu que mandei entulhar. Nós pagamos caçamba de pedra.... Porque aqui era só na pedra... Só essa casa aqui foi umas vinte caçambadas de pedra... Agora isso aqui tudo era mangue... Isso aqui quando eu entulhei era seco... Eu peguei a água bem aqui no peito pra eu poder adquirir esse quintal [...]

Quando a senhora chegou à casa de palafita já estava construída?

Já estava construída. Lá na frente já era taipa. Toda de taipa, toda "rebocadinha". Aí nós alugamos ela. Aí de alugada nós já compramos [...] o fundo que era maré [...] Isso daqui a gente mandou entulhar tudo. Desde lá da frente até aqui. $\mathrm{Na}$ frente era de taipa, tinha só um quarto [...] essa área aí foi a DENIT que me deu [...] porque quando foram construir a ponte, as casas abaixaram tudinho. Minha casa quebrou a parede todinha [...] danificou minha parede todinha aí eu fiquei na rua, aí o Januário veio aqui e eu disse: "Não. Eu quero que

7 Pertencente ao bairro da Camboa, a Vila Gorete ganhou esse nome por causa de dois pescadores locais que acharam uma pedra parecida com a Santa Gorete. A rua então foi batizada por padre Nazareno, antigo padre da Igreja dos Remédios, com esse nome. Por causa da santa, o local ganhou uma pequena capela com imagem dela.

8 Cinzeiro de Fábrica, denominação que os moradores da Vila Gorete dão para a localização da rua, uma vez que ela se encontra atrás do terreno da antiga fábrica da Camboa. 
ele venha fazer minha parede, eu não tenho condição de fazer”. Eles vieram e fizeram a parede tão, tal que nem botaram "radier", como chamam, que é pra aguentar, né...? Eles não colocaram, só fizeram a parede direto [...]

A senhora sabe quantos moradores tinham naquela época, já estava populoso?

Ah!Já tinha um bocado de "moradorzinhos". Morando por cima dos assoalhos, já. Tinha muito, bastante.

Antes da senhora chegar aqui já tinha visto palafita alguma vez ou só viu quando chegou?

Não, eu já tinha visto, porque quando eu vim morar em 1967 no Jenipapeiro era palafita. Minha casa era lá em cima. Quando a maré vinha, eu já estava ajeitando as coisas tudinho para não molhar. Eu morava em palafita...

Era a senhora tinha uma rotina diária de colocar as coisas pra cima pra não molhar?

Sim. Lá que eu morava em uns quartinhos que a gente alugou... Meus filhos ainda caíram dentro da maré (Albertina, entrevista em 1/1/2016).

Assim como Galego, Albertina também acompanhou as mudanças das moradias na área da Camboa. Quando a moradora chegou, em 1971, sua casa era alugada, de taipa e com os fundos para o mangue. Com o processo de urbanização da cidade, e a construção da ponte Bandeira Tribuzzi, observa-se a possibilidade de aterro dessas casas, como relataram Galego e Albertina, que utilizaram o entulho para aterrar e fazer melhorias nas casas. A moradora ainda teve a oportunidade de aumentar o terreno de sua propriedade, cedido pelos responsáveis da obra na ponte, fazendo assim o processo de aterro com pedras.
Observa-se pelo relato dos moradores que o processo de entulho começa na parte da frente da casa deixando por último os fundos. Com esse processo, as melhorias nas residências são gradativas, na medida em que são aterradas há a possibilidade de aumentar para mais cômodos. No caso dos dois moradores acima, as áreas onde estão situadas suas casas foram completamente aterradas, não tendo mais suas casas ligação com a maré.

$\mathrm{Na}$ antiga favela do Maruim, no bairro da Liberdade, no ano de 2015, quando eu fazia pesquisa de campo, algumas casas ainda não haviam sido removidas. Elas, apesar de estarem na mesma estrutura das palafitas, estavam com sua parte da frente já entulhadas, permanecendo com os fundos ainda para o mangue. Eram poucas casas que ainda permaneciam ali, pois a maioria dos moradores tinha sido transferida para os apartamentos do PAC ou estava recebendo aluguel social.

Uma das moradoras da "favela do Maruim", chamada Márcia, informou que a maioria dos moradores da favela do Maruim veio da Baixada Maranhense. Ela, quando mudou, logo se estabeleceu na área, pois sua família já estava residindo ali. A interlocutora tinha um pequeno comércio na rua, em dois compartimentos de alvenaria, o que indicava que os melhoramentos nas casas foram realizados de maneira gradativa, 
como os entulhos. A moradora, assim como sua vizinha Vitória, que também residia no Maruim, contou que os moradores têm orgulho do que construíram e "entulharam". Assim como no bairro da Camboa, eles se reuniram para fazer as melhorias na rua e nas casas. Juntaram-se para pagar as caçambas de entulho e organizaram-se para puxar a água e fazer o esgoto da rua, como Vitória destaca: "as casas da rua já estão no seco porque foram entulhadas", quando se referia ao aterro feito pelo programa do PAC.

$\mathrm{O}$ que se percebeu nas declarações das moradoras são os intensos laços estabelecidos no local de moradia. Desde os laços familiares, como também de vizinhança. Ao descreverem o processo de melhoramento realizado na sua "favela", as moradoras não hesitaram em reforçar o orgulho que sentiam ao fazer tudo em grupo, com ajuda dos vizinhos, o que demonstra também os laços de solidariedade entre eles. Apesar das dificuldades enfrentadas no local de moradia, essas não foram condicionantes para o desejo de saída dessas pessoas. Pelo contrário, foram importantes para o fortalecimento dos laços de vizinhança; tendo em vista o abandono do poder público para com essas populações, os moradores voltaram-se para as formas de organizações comunitárias e mutirões como forma de resolução dos problemas em relação à habitação e aos equipamentos urbanos, o que é histórico nas mobilizações e luta por moradia nesta área.

O que se pode identificar é que os bairros passam por processos de melhoramentos realizados pelos próprios moradores, em formas de mutirões e por processos de organizações coletivas. As favelas, aos poucos, iam sendo entulhadas e assim os bairros iam sendo aterrados, e com isso novas moradias iam se estabelecendo ali, assim como os possíveis melhoramentos nas casas.

\section{CONCLUSÃO}

A proposta desde artigo foi fazer uma análise dos bairros da Camboa e da Liberdade levando em conta as especificidades de ocupação desses bairros, sendo destino de muitas famílias migrantes de Alcântara e litoral ocidental maranhense.

As áreas às margens do rio Anil possibilitaram não apenas a ocupação e o adensamento territorial dando origem aos bairros, como também possibilitou, de certa forma, a continuidade de pequenas atividades, como a pesca, a criação de pequenos animais e a relação com pequenos povoados através do mar.

Os bairros da Camboa e da Liberdade exemplificam o que Pina-Cabral e Godoi (2014) chamam de vicinalidade, proximidades espaciais que devem ser vistas como formas de prolongar a morada, de criar locais de vida e identidade. Os 
bairros representam esse espaço de circulação de pessoas como também circulação de coisas e símbolos, interações de pessoas que estão além de seus povoados de origem.

A partir dos dados e das experiências de campo com algumas familias dos bairros, é importante compreender que a noção de casa se constitui de forma diferente nesses espaços. É pelos mutirões e autoconstruções, formas de solidariedade e cooperação, que muitas famílias migrantes encontram nos centros urbanos a maneira de ter acesso à moradia. A relação que essas populações têm com a casa, está fora da relação capitalista, que envolve a compra e a venda da força de trabalho. A relação com a casa envolve afetos, recordações, histórias de solidariedade e dificuldades compartilhadas. "Entulhar" representa uma forma de resistência, adaptação, e era sinônimo de orgulho para muitas familias que venceram as dificuldades e conseguiram constituir seus lares nestes bairros.

Pensar a cidade a partir da experiência de vida de muitas familias que deixaram seus territórios e se estabeleceram ali, rompendo as fronteiras espaciais e fazendo desses bairros, locus de novas territorialidades é pensar a multiplicidade de realidades sobre a cidade que não se encaixam em conceitos tão gerais. 


\section{REFERÊNCIAS}

Assunção, Ana Valéria Lima. 2017. “Quilombo urbano”, Liberdade, Camboa e Fé em Deus: identidade, festas, mobilização política e visibilidade na cidade de São Luís, Maranhão. Dissertação de mestrado, Programa de Pós-Graduação em Cartografia Social e Política da Amazônia, Universidade Estadual do Maranhão, São Luís.

Burnett, Carlos Frederico Lago e Silva, Joana Barbosa Vieira. 2015. O mapa cultural do rio Anil como instrumento de integração urbana e transformação espacial. XVI ENAPUR: espaço, planejamento e urgência. 6 (1):1:18.

Caldeira, Teresa Pires do Rio. 2000. Cidade de muros: crime, segregação e cidadania em São Paulo. São Paulo: Edusp.

Cardoso, Maria Sueli Dias. 2008. Só vivo da pesca: estratégias de reprodução de famílias camponesas no meio urbano - entre Alcântara e São Luís, Maranhão. Dissertação de mestrado, Programa de PósGraduação em Ciências Sociais, Universidade Federal do Maranhão, São Luís.

Certeau, Michael. 1998. A invenção do cotidiano. Petrópolis: Vozes.

Curvelo-Matos, Heloísa Reis. 2014. Análise toponímica de 81 nomes de bairros de São Luís-MA. Tese de doutorado, Universidade Federal do Ceará, Centro de Humanidades, Departamento de Letras Vernáculas, Programa de Pós-Graduação em Linguística, Fortaleza.

Durham, Eunice. 1982. Os problemas atuais da pesquisa antropológica no Brasil. Revista de Antropologia. 25:159:170.

Godoi, Emilia Pietrafesa. 2014. Mobilidades, encantamento e pertença: o mundo ainda está rogando, porque ainda não acabou. Revista de Antropologia de São Paulo. 57 (2):143:170.

Maranhão. 1923. Álbum do Maranhão. http://casas.cultura.ma.gov.br/portal/sgc/modulos/sgc_bpbl/ acervo_digital/arq_ad/201408272214321409188472_95931409188472_9593.pdf

Koyaanisqatsi: uma vida fora de equilíbrio. 1983. Direção e produção: Godfrey Reggio. Música: Philip Glass. Santa Fé: Institute for Regional Education.

Lopes, Raimundo.1924. A civilização lacustre do Brasil. Boletim do Museu Nacional. 1 (2):87:109.

Loureiro, Violeta Refkalefsky. 2001. Pressupostos do modelo de integração da Amazônia aos mercados nacional e internacional em vigência nas últimas décadas: a modernização às avessas. Sociologia na Amazônia: debates teóricos e experiências de pesquisa, pp.47-70. Belém: UFPA.

Luz Silva, Lindimberg. 2007. Quilombolas entre Alcântara e São Luís. Trabalho de Conclusão de Curso, Curso de Ciências, Universidade Federal do Maranhão, São Luís. 
Menezes, Tainá Marçal Santos; Perdigão, Ana Klaudia e Pratschke, Anja. 2015 O tipo palafita amazônico: contribuições ao processo de projeto de arquitetura. Oculum Ensaios. 12(2): 23: 254.

Monnerat, Silvia e Vieira, Cleiton. 2021. Contextos urbanos na perspectiva das Ciências Sociais. Revista Argumentos. 6 (1): 4:29.

Navarro, Alexandre Guida. 2017. As cidades lacustres do Maranhão: as estearias sob um olhar histórico e arqueológico. Revista Diálogos. 21 (3): 126:142.

Nota sobre a Camboa. O fornal (São Luís), 31 de maio de 1916.

Nota sobre a Cia de Fiação e Tecidos Maranhense. A Cruzada, 1891.

Pereira, Jesus Marmanillo. 2010. Engajamento militante e luta pela moradia em São Luís entre as décadas de 1970 e 1980. Dissertação de mestrado, Programa de Pós-Graduação em Ciências Sociais, Universidade Federal do Maranhão, São Luís.

Pina-Cabral João e Emília Pietrafesa de Godoi. 2014. Vicinalidades e Casas Partíveis. Revista de Antropologia. 57 (2): 11:21.

Ribeiro Junior, José Reinaldo Barros. 2001. Formação do espaço urbano de São Luís: 1612-1991. 2 ed. São Luís: Ed FUNC.

Sennett, Richard. 2016. Carne e pedra: o corpo e a cidade na civilização ocidental. Rio de Janeiro: Edições Bestbolso.

Silva, Ana Lúcia Duarte. 1997. De Matadouro à Liberdade: a formação histórica-cultural de um bairro de São Luís. Trabalho de Conclusão de Curso, Universidade Federal do Maranhão, São Luís.

Silva, Joana e Kapp, Silke. 2016. As palafitas do Rio Anil: memória de uma cultura construtiva em vias de erradicação. Belo Horizonte: Grupo MOM. Não publicado.

Simmel, G. 2005. As grandes cidades e a vida do espírito (1903). Mana. 11(2): 577:591. 